\title{
The Effect of Platelet-Rich Plasma to Orthodontic Tooth Movement
}

\author{
Erliera Sufarnap \\ Department of Orthodontic \\ Faculty of Dentistry, Universitas Sumatera Utara \\ Medan, Indonesia \\ drg.erliera@yahoo.com
}

\author{
Ervina Sofyanti \\ Department of Orthodontic \\ Faculty of Dentistry, Universitas Sumatera Utara \\ Medan, Indonesia
}

\author{
Syafrudin Ilyas \\ Department of Biology \\ Faculty of Mathematics and Science, Universitas Sumatera Utara \\ Medan, Indonesia
}

\begin{abstract}
Platelet-Rich Plasma already used by oral surgeon and periodontics due to enhance the bone remodels. Orthodontic tooth movement affects bone remodeling process, bone resorption on the pressure side and new bone formation on the tension side. This is the objective of this research, to observe the effect of PRP to orthodontic tooth movement. This research was conducted in pure clinical experimental to Guinea pig. Nineteen Guinea pigs separated into two groups, control and PRP groups. Blood homolgue from donors was processed became PRP and the highest platelet counted number injected to samples without activator. 4 times measurements were studied: $6,9,12$ and 24 days of orthodontic tooth movement by rubber separator between central incsicors. Distance between central insicors was measured with digital caliper (0.01 accuracy). Platelet mean measured were $430.00 \pm 57.32\left(10^{\wedge} 3 / \mathrm{mL}\right)$. Distance measurements were not significantly different between PRP and control groups at each time point of measurement $(p>0.05)$ with t-test unpaired analysis, and neither does analyzed with mixed-repeated measured ANOVA ( $p=0.935$ ) but analysis between 4 times point of measurement and each groups with Greenhouse-Geisser correction showed that mean distance measurements differed significantly between at least three time points measurements $\quad(\mathbf{F}(2,132 ; 36,243)=3,464, \quad p<0.039)$. In conclusion to this research, we couldn't see any significantly different between both groups with 4 times points of measurement but there were statistically significant effects of time simultaneously for each groups.
\end{abstract}

Keywords-platelet-rich plasma, orthodontic tooth movement, guinea pig

\section{INTRODUCTION}

Tooth movement physiology has two sides mechanism, pressure area which is the bone compressed by loads of the mechanical force of orthodontic appliance. Resorption happened at this pressure or compression side of the alveolar bone and periodontal ligament which will activate PDL progenitor cells to differentiate into osteoclast $[1,2]$. In the other side, as a response to the deformation, the tension area which is the apposition area activates fibroblasts and osteoblasts in the PDL as well as osteocytes in the bone to localized apposition to alveolar bone [1].

The phenomenon of molecular biology and genomes for tooth movement and stabilization in orthodontic treatment are complex. In the beginning from coordination of biochemistry reaction around cells, protein expression pattern, cells synthesize, cell divisions, cell proliferation until cells differentiated have vary every patient $[1,3,4]$. Cell synthesizes and molecular release such as neurotransmitter, cytokines, and growth factors (GFs), colony stimulating factors, arachidonic metabolic acid [2].

Orthodontics' mechanical low force and accelerated tooth movement now become a trend topic discussed generally. The longer the treatment the more gets negative effects on oral hygiene, root, alveolar and gingival embrasure resorption [5-7]. Wilcko found a method of surgery procedure to provide a periodontal ligament-mediated acceleration in tooth movement reducing some thin layers of an alveolar and many more researchers tried to find methods to accelerate tooth movement [8]. Brahmanta's researched was a hyperbaric oxygen therapy as an adjuvant for orthodontic, Nishimura tried to use vibration on teeth before treatment, Xue et al., with LIPUS (low intensity pulsed ultrasound) and the last was Gulec et al., and Liou with the injected platelet-rich plasma (PRP) to induce the teeth movement [7,9-12].

Platelet-rich plasma (PRP) is a processed by centrifuging blood autologous product derived from whole blood $[11,13]$. Platelet-rich plasma (PRP) is an easily accessible source of growth factors to support bone and soft-tissue healing by increasing cellular proliferation, matrix formation, osteoid production, connective tissue healing, angiogenesis, and collagen synthesis [13.14]. Platelet-rich plasma (PRP) has been well known specially in preparation for a dental implant or promoting an alveolar bone by periodontologist [15].

Growth factors and other substances served to accelerate the wound-healing process [13] while others 
found no additional benefit [16]. Graziani et al., mentioned that PRP can play an inhibitory role in bone metabolism in a concentration-dependent fashion [4] so that PRP could be succeed in accelerating tooth movement in rats by reducing the bone density [11] and accelerating tooth movement in human [12]. The clinical usefulness of PRP remains controversial especially for orthodontic tooth movement [17]. There were still a few research mentioned about PRP effects to orthodontic tooth movement especially for human.

Therefore the purpose of this research were to observe PRP sub mucous injection to orthodontic tooth movement in guinea pig which it has resemblance to human so that we can analyze the bone remodeled in histology analysis [18].

\section{MATERIALS AND METHODS}

This research was a clinical experimental analytic research. The clinical experimental study with 24 young Guinea pigs (2-3 months) with mean of weight 250-400 grams. There were nurtured at Biology Department of University Sumatera Utara for two months. This study was approved by the Animal Research Ethics Committee (AREC) at Biology Department of Mathematics and Natural Science Faculty (protocol approval number 497/KEPH-FMIPA/2017), University of Sumatera Utara, Medan Indonesia.

Guinea pigs were divided into three groups: donor group (euthanized for the preparation of PRP; n 4), control group (C group, n 10), and platelet-rich plasma injection group (PRP group, n 10-1). These 2 groups, 4 time points were studied on days $6,9,12$, and 24 . The animals were fed with chopped carrots diet to prevent the pulled out of the rubber separator. All procedures were completed under general anesthesia with intramuscular injection administration, donor groups was euthanized with pure ketamine $(150 \mathrm{mg} / \mathrm{kg})$ without xylazine which didn't distribute in Indonesia recently [18].

The production of PRP began with a 9-12 mL homologous blood sample from the donor animal via cardiac puncture. Blood withdrew from cardiac directly to 1.8 or $2.7 \mathrm{ml}$ tube which contained a buffer Natrium citrate $3.2 \%$ as an anticoagulant. $0.5 \mathrm{ml}$ whole blood sample set apart and analyzed for observe the concentration of whole blood test analysis such as red blood cell analysis, platelets and leukocytes in whole blood with an analyzer blood machines (sysmex XT2001). The blood sample was centrifuged with Eppendorf centrifuge machine at $1500 \mathrm{rpm}$ (264 rcf) for 5 minutes to process the whole blood become platelet rich plasma. Plasma was drawn off the top and one per four plasma in the bottom separated from red blood cell has been moved to the new spuit needle which contained the buffy coat of PRP product. Platelet in plasma as PRP concentration then analyzed again with the same machines. The mean difference was then calculated and the highest platelets in PRP concentrate was then injected to the guinea pig fresh after processed. Other PRP sampled were brought to store at $-80^{\circ} \mathrm{C}$ freezers for future biochemical analysis

Force for orthodontic tooth movement was given by power-O (Ormco) as a rubber separator between central incisors after PRP injection. Power-O changed gradually every 4 times point of measurements. Measurement for tooth movement distance was done 5 minutes after removing the rubber separator as a biological adaptation after orthodontic force released. Comparison was made between control group and PRP group to compare the distance effects for each different time points measurement.

The data were processed with IBM*SPSS Statistic (version 21). The results are expressed as means and standard deviations, dependent t-test analysis to compare inter-rater reliability data for tooth movement distance, independent t-test analysis to compare two groups variable for each time point of measurements, and also one-way repeated measures analysis of variance was used in repeated measurements for each of two groups for all 4 times point and also mixedANOVA for analyzed correlation between two groups and 4 time point of measurement. The significance level was set at $\mathrm{P}<0.05$

\section{RESULTS}

In the beginning of trials, The sample consists of 2 groups divided into 10 samples for control groups and 10 samples for trial groups (PRP groups). Before day 12 , one sample was excluded due to unhealthy and dead.

The mean for platelet's count in whole blood cells from 4 donor samples were $223.25 \pm 33,69\left(10^{\wedge} 3 / \square \mathrm{L}\right)$ and the mean for platelet's concentration count in Platelet rich plasma were 430.00 $\pm 57,32\left(10^{\wedge} 3 / \square \mathrm{L}\right)$. The platelet's count raised 1,93 fold by single centrifugation method. The platelet concentration's for PRP injection to all samples at PRP group were $507.00\left(10^{\wedge} 3 / \square \mathrm{L}\right)$ which had 2,45 fold platelet's counts numbers.

The inter-rater correlation coefficient differences values between two observer were above 0.057 for all groups of 4 times point of distance measurements at day $6,9,12$ and 24, confirming the reliability of the measurements. The tooth movement increased high at day 6 from the base line and also gradually increased from day 6 to day 9 for both groups and day 9 to 12 only at PRP group (Figure 1). It seemed slower at day 9 to 12 for the control groups and day 12 to 24 for both groups.

At Table I, statistically compared between both groups for each time point of measurement (analyzed with unpaired t-test) found that there were not any of the each time measurement had significantly different with the smallest $\mathrm{p}$ value were still $0.054(\mathrm{p}>0.05)$ at day 12. It seemed the tooth movement in PRP groups still increased while in control group was already stabilized.

Another statistically analysis were a mixed-repeated measured of ANOVA, neither found significantly main 
effect of intervention (PRP injection on PRP group) than control group with p value 0.935 ( $p>0.05)$.

As if we analyzed for each groups, there were found statistically significant at least for three time points measurements at each groups with Greenhouse-Geisser correction $(\mathrm{F}(2,132 ; 36,243)=3,464, \mathrm{p}<0,039)$.

TABLE I. MEAN OF DISTANCE'S MEASUREMENT OF TOOTH MOVEMENT FOR PRP INJECTION

\begin{tabular}{|c|c|c|c|c|c|}
\hline \multirow{2}{*}{ Group } & \multicolumn{5}{|c|}{ Distance of Toth Movement (mm) } \\
\cline { 2 - 6 } & Day 6 & Day 9 & Day 12 & Day 24 & $\mathbf{P}^{\mathbf{b}}$ \\
\hline Control & 0.840 & 0.956 & 0.976 & 1.046 & 0.001 \\
Groups & \pm 0.063 & \pm 0.034 & \pm 0.042 & \pm 0.054 & \\
$(\mathrm{n}=10)$ & & & & & \\
\hline PRP Groups & 0.777 & 0.948 & 1.026 & 1.061 & 0.001 \\
$(\mathrm{n}=9)$ & \pm 0.113 & \pm 0.085 & \pm 0.061 & \pm 0.049 & \\
\hline $\mathbf{P}^{\mathbf{a}}$ & $\mathbf{0 . 1 6 2}$ & $\mathbf{0 . 7 9 2}$ & $\mathbf{0 . 0 5 4}$ & $\mathbf{0 . 5 3 4}$ & $\mathbf{P}^{\mathbf{c}}$ \\
& \multicolumn{7}{|c|}{} & $\mathbf{0 . 9 3 5}$ \\
\hline
\end{tabular}

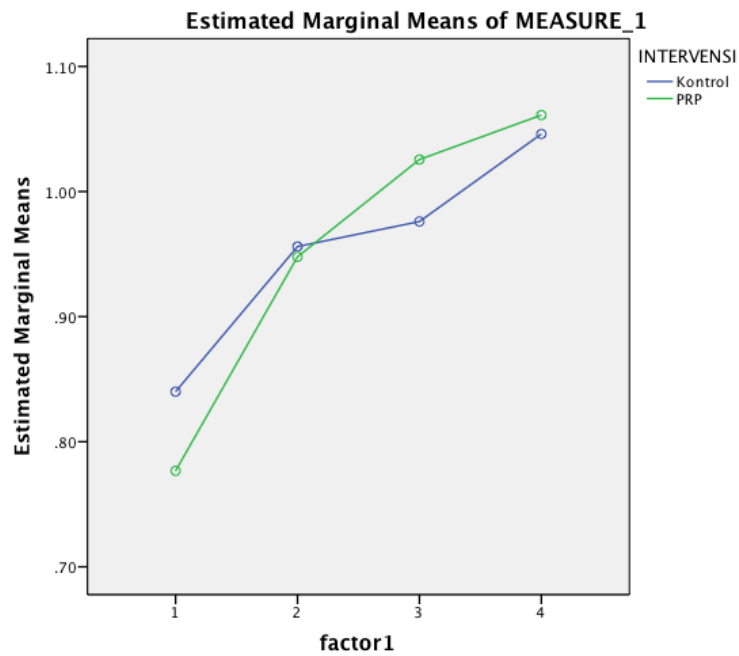

Figure 1. Tooth movement on different days for Control group and PRP group.

\section{DISCUSSION}

Nayak said that orthodontic mechanical forces are known to have various effects on the alveolar process, such as cell deformation, inflammation, and circulatory disturbances [19], the longer the treatment the more gets negative effects on oral hygiene, root, alveolar and gingival embrasure resorption [5-7]. In this research the distance of teeth movement were significantly increased from base line. Every process on tooth movement conditions affecting cell differentiation, cell repair, and cell migration, and it is driven by numerous molecular and inflammatory mediators through the alveolar bone remodeling, periodontal ligament, cementum and gingiva [19-21].

Tooth movement in this research seemed not significantly different between 4 time points of measurement but as far we could see in Figure 1 that it was almost had differences that the tooth movement in day 12 the tooth movement were still increased in the PRP groups as in the control groups were already stabilized. Platelets isolated from peripheral blood known as platelet rich plasma are an autologous source of many growth factors which are stored in the $\alpha$ granules of platelets [14]. Marx mentioned that the growth factors in PRP include platelet-derived growth factor (PDGF), insulin-like growth factor (IGF), vascular endothelial growth factor (VEGF), and transforming growth factor- $\beta$ (TGF- $\beta$ ) (cit. Raja et al.) [14]. Clinical trials suggest that the combination of bone grafts and growth factors contained in PRP and PRF may be suitable to enhance bone density and accelerating tooth movement $[11,14]$.

Some authors mentioned the growth factors should be triggered by the activation of platelets, which may be initiated the formation of PRP gel by a variety of substances or stimuli, such as thrombin, calcium chloride, collagen, thrombin or bovine thrombin to initiate $[11,13,14,20]$ but other author said that the prolonged we need for growth factor to be active the more we should not need any activation before initiation of the PRP [12]. So those in this research the PRP products has not activated before injection to the samples. Roberts also mentioned that the limiting factor in the rate of tooth movement is bone resorption by the osteoclasts to the bone which is limited by the compression and necrosis of the PDL. Undermining resorption is needed if the vascularity of the PDL is compromised in the area of maximal compression [5]. Verna mentioned that the influence of different bone turnover rates on quantify and quality of orthodontic tooth movement itself and for the future studies it needs to use continues force to apply at the sample [22].

The limitation of this study was the lack evaluation of histological results of each time point measurements from samples. It supposed that we can compare between histological cells analysis with this distance measurement based on the fact. And for the future studies, it is recommended to use bone formation markers for detecting the molecular bone remodeling activity and also need to use the fibroblast markers for detecting the periodontal ligament as a morphogenic protein to immunohistochemically analysis for better understanding of the new bone formation mechanism completely.

In conclusion to this research, we couldn't see any significantly different between both groups with 4 time points of measurement but there were statistically significant effects of time simultaneously for each groups. It still needs further studies to continue this research.

\section{ACKNOWLEDGMENT}

Acknowledgments are addressed to Research Institution University of Sumatera Utara at the expense of this study from TALENTA funding in 2017.

\section{REFERENCES}

[1] S. Henneman, J.W. Von den Hoff, J.C. Maltha, "Mechanobiology of tooth movement," European Journal of Orthodontics, vol. 30, pp. 299-306, June 2008.

[2] K. Reitan, Biomechanical principles and reactions. In: Graber TM, Swain BF, editors. Current orthodontic concepts and techniques, $3^{\text {rd }}$ ed. Philadelphia: W. B. Saunders, 1985. 
[3] R.S. Masella, M. Meister, "Current concepts in the biology of orthodontic tooth movement," Am. J. Orthod. Dentofacial Orthop., vol. 129, pp. 458-68, April 2006.

[4] F. Graziani, S. Ivanovski, S. Cei, F. Ducci, M. Tonetti, M. Gabriele, "The in vitro effect of different PRP concentrations on osteoblasts and fibroblasts," Clin. Oral. Impl. Res., vol. 17, pp. 212-219, May 2006.

[5] W.E. Roberts, S. Huja, J.A. Roberts, "Bone modeling: biomechanics, molecular mechanisms, and clinical perspectives," Semin. Orthod., vol. 10, pp. 123-61 June 2004.

[6] M. Seifi, M.R. Badiee, Z. Abdolazaimi, P. Amdjadi, "Effect of basic fibroblast growth factor on orthodontic tooth movement in rats," Cell J. Autumn, vol. 15(3), pp. 230-237, August 2013.

[7] M. Nishimura, M. Chiba, T. Ohashi, M. Sato, Y. Shimizu, K. Igarashi, M. Mitani, "Periodontal tissue activation by vibration: Intermittent stimulation by resonance vibration accelerates experimental tooth movement in rats," Am. J. Orthod. Dentofacial Orthop., vol. 133, pp. 572-83, January 2008.

[8] W. Wilcko, M.T. Wilcko, "Accelerating tooth movement: The case for corticotomy-induced orthodontics," Am. J. Orthod. Dentofacial Orthop., vol. 144(1), pp. 4-13, July 2013.

[9] A. Brahmanta, Soetjipto, I.B. Narmada IB, "The expression of collagen type-I in the tension area of orthodontic tooth movement with adjuvant of hyperbaric oxygen therapy," International Journal of ChemTech Research, vol. 9(07), pp 199-204, 2016

[10] H. Xue, J. Zheng, Z. Cui, X. Bai, G. Li, et al., "Low-intensity pulsed ultrasound accelerates tooth movement via activation of the BMP-2 signaling pathway," PLoS ONE, vol. 8(7), pp. e68926, July 2013.

[11] A. Gulec, C.B. Banu, A. Cumbuk, U. Uslu, B. Alev, A. Yarat, "Effects of local platelet-rich plasma injection on the rate of orthodontic tooth movement in a rat model: A histomorphometric study," Am. J. Orthod. Dentofacial Orthop., vol. 151, pp. 92-104, May 2017.

[12] E.J.W. Liou, "The development of submucosal injection of platelet rich plasma for accelerating orthodontic tooth movement and preserving pressure side alveolar bone," APOS Trends Orthod., vol. 6, pp. 5-11. October 2017.
[13] R.G. Smith, C.G. Gassmann, M.S. Campbell, "Platelet-rich plasma: Properties and clinical applications," The Journal of Lancaster General Hospital, vol. 2(2). pp. 73-77. July 2007.

[14] V.S. Raja, E.M. Naidu, Platelet-rich fibrin: Evolution of a second-generation platelet concentrate," Indian Journal of Dental Reaserch, vol. 19(1), pp. 42-6, August 2008.

[15] A. Malhotra, M.H. Pelletier, Y. Yu, W.R. Walsh, "Can plateletrich plasma (PRP) improve bone healing? A comparison between the theory and experimental outcomes," Arch. Orthop. Trauma Surg., vol. 133, pp. 153-165, November 2012.

[16] S.J. Froum, S.S. Wallace, D.P. Tarnow, S.C. Cho, "Effect of platelet-rich plasma on bone growth and osseointegration in human maxillary sinus grafts: three bilateral case reports,' International Journal of Periodontics and Restorative Dentistry, vol. 22(1), pp. 45-53, 2002.

[17] R.E. Marx, Platelet-rich plasma: evidence to support its use,” J. Oral Maxillofac Surg., vol. 62, pp. 489-496, Desember 2004.

[18] V. Dang, S. Bao, A. Ault, C. Murray, J.M. Mills, C. Chiedi, et al., "Efficacy and safety of five injectable anesthetic regimens for chronic blood collection from the anterior vena cava of guinea pigs" Journal of the American Association for Laboratory Animal Science, vol. 47(6), pp. 56-60, November 2008.

[19] B.N. Nayak, K.A. Galil, W. Wiltshire, P.C. Lekic, "Molecular biology of orthodontic tooth movement. J. Dent Oral Health, vol. 1, pp. 101, September 2013.

[20] J. Araki, M. Jona, H. Eto, N. Aoi, H. Kato, H. Suga, et al., "Optimized preparation method of platelet-concentrated plasma and noncoagulating platelet-derived factor concentrates: Maximization of platelet concentration and removal of fibrinogen," Tissue Eng. Part C Methods, vol. 18(3), pp. 176185, March 2012

[21] H. El-Sharkawy, A. Kantarci, J. Deady, H. Hasturk, H. Liu, M Alshahat, et al., "Platelet-rich plasma: growth factors and proand anti- inflammatory properties. J. Periodontol., vol. 78, pp 661-9, 2007.

[22] C. Verna, M. Dalstra, B. Melsen, "The rate and the type of orthodontic tooth movement is influenced by bone turnover in a rat model," European Journal of Orthodontic, vol. 22, pp. 343 352,2000 